Case Report

\title{
Autoimmune Hemolytic Anemia Combined with Sepsis After Abdominal Trauma Surgery
}

\author{
Gil Seong Moon a, Young Un Choi b,c, Hongjin Shim b,c, Ji Young Jang d,* \\ ${ }^{a}$ Department of Surgery, Wonju Severance Christian Hospital, Wonju, Korea \\ ${ }^{b}$ Regional Trauma Center, Wonju Severance Christian Hospital, Wonju, Korea \\ ${ }^{c}$ Department of Surgery, Yonsei University Wonju College of Medicine, Wonju, Korea \\ ${ }^{d}$ Department of Surgery, National Health Insurance Service Ilsan Hospital, Goyang, Korea
}

\section{Article history:}

Received: December 19, 2019

Revised: September 8, 2020

Accepted: January 15, 2021

\section{${ }^{*}$ Corresponding Author:}

Ji Young Jang

Department of Surgery, National Health

Insurance Service Ilsan Hospital,

100 Ilsan-ro, Ilsan-donggu, Goyang,

Gyeonggi-do, Korea

E-mail: drjangjiyoung@gmail.com

\section{ORCID}

Gil Seong Moon

https://orcid.org/0000-0002-5573-8585

Young Un Choi

https://orcid.org/0000-0003-2410-7788

Hongjin Shim

https://orcid.org/0000-0003-3073-3806

Ji Young Jang

https://orcid.org/0000-0001-6372-4194

\begin{abstract}
Intra-abdominal infection is a common, serious complication in patients undergoing emergency abdominal surgery following blunt abdominal trauma. Infectious conditions increase the incidence of autoimmune hemolytic anemia (AIHA), but reports of AIHA occurring after abdominal trauma surgery are rare. Therefore, we report a case of sepsis due to fasciitis and AIHA after abdominal trauma surgery which was successfully managed following the appropriate treatment of both conditions.
\end{abstract}

Keywords: abdominal injuries, anemia, autoimmunity, hemolytic, sepsis

\section{Introduction}

Autoimmune hemolytic anemia (AIHA) is a disorder of the immune system that results from the production of autoantibodies which act on red blood cells [1], and common causes include autoimmune diseases and infections [2]. The incidence of intra-abdominal infection has been reported to be $20 \%$ in patients undergoing a laparotomy following blunt abdominal trauma and is the most common, serious complication [3]. However, only a limited number of cases of AIHA after abdominal trauma surgery have been reported. Here, we report a case of sepsis due to fasciitis and AIHA which was diagnosed in a patient who underwent emergency abdominal surgery following blunt trauma, which was successfully managed following the appropriate treatment of both conditions.

\section{Case Report}

A 54-year-old woman without any relevant medical history visited the trauma center with abdominal pain caused by a car accident. Her initial blood pressure, pulse rate, and body temperature were $95 / 51 \mathrm{mmHg}, 131$ beats/ minute, and $35.5^{\circ} \mathrm{C}$, respectively, and markings caused by the seat belt were observed on her abdomen. A physical examination of the abdomen revealed that it was rigid and distended. Moreover, tenderness and rebound tenderness was observed over the entire abdomen. An extended focused assessment with sonography for trauma identified a large accumulation of fluid in the abdomen. Abdomino-pelvic computed tomography (CT) confirmed herniation of the right colon and small bowel through the ruptured site of the right abdominal wall and a large amount of hemoperitoneum, and emergency surgery 
was performed (Figure 1). Approximately $1,000 \mathrm{cc}$ of blood was observed in the abdominal cavity and an abdominal wall defect $(10 \times 5 \mathrm{~cm})$ was identified in the right flank area. Multiple mesentery injuries were identified, and bleeder ligation and repair of the small bowel mesentery were performed. Two small bowel perforation sites were primarily repaired. Segmental resection of the small bowel, and end to end anastomosis were performed on the small bowel, $270 \mathrm{~cm}$ distal from the Treitz ligament. Color change of the herniated ascending colon and ileocolic vessel injury were identified. A right hemicolectomy with ileo transverse colostomy was performed and the right abdominal wall defect was repaired.
After surgery, the patient was treated in the intensive care unit for hypovolemic shock and sepsis. From the time of admission, 10 units of packed red blood cells and 7 units of fresh frozen plasma were transfused into the patient. On the $5^{\text {th }}$ day of hospitalization, the patient was transferred to the general hospital ward where mild jaundice was observed. On the $7^{\text {th }}$ day of hospitalization, the total serum bilirubin level was 4.32 $\mathrm{mg} / \mathrm{dL}$, and it increased daily reaching $37.55 \mathrm{mg} / \mathrm{dL}$ on the $12^{\text {th }}$ day of hospitalization (Table 1). Following surgery, anemia was consistently observed without hemorrhage. Hemoglobin levels decreased to $6.7 \mathrm{~g} / \mathrm{dL}$ on the $12^{\text {th }}$ day of hospitalization, and the autoantibody test was positive.
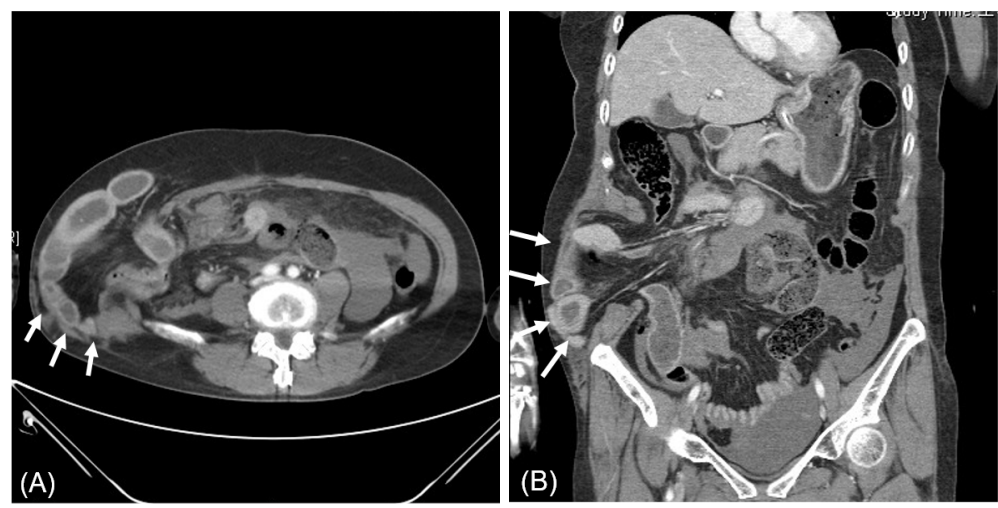

Figure 1. Computed tomography image of the right abdominal wall injury. Herniated bowel through an abdominal wall defect was identified (white arrows). (A) Axial view, (B) coronal view.

Table 1. Summary of patient's progress.

\begin{tabular}{|c|c|c|c|c|c|c|c|c|c|c|c|c|c|}
\hline \multirow{2}{*}{$\begin{array}{c}\text { Patient } \\
\text { parameters }\end{array}$} & \multicolumn{13}{|c|}{ Hospital day } \\
\hline & 2 & 7 & 9 & 10 & $\begin{array}{c}12 \\
(9 / 21)\end{array}$ & $\begin{array}{c}13 \\
(9 / 22)\end{array}$ & $\begin{array}{c}14 \\
(9 / 23)\end{array}$ & $\begin{array}{c}16 \\
(9 / 25)\end{array}$ & $\begin{array}{c}17 \\
(9 / 26)\end{array}$ & $\begin{array}{c}19 \\
(9 / 28)\end{array}$ & $\begin{array}{c}21 \\
(9 / 30)\end{array}$ & $\begin{array}{c}32 \\
(10 / 11) \\
\end{array}$ & $\begin{array}{c}37 \\
(10 / 16) \\
\end{array}$ \\
\hline $\begin{array}{c}\text { WBC } \\
(/ \mathrm{mm} 3)\end{array}$ & 6,020 & 10,620 & 12,770 & 17,160 & 20,970 & 14,260 & 9,960 & 5,220 & 4,870 & 4,830 & 5,640 & 2,520 & 6,720 \\
\hline $\begin{array}{l}\text { Neutrophil } \\
(\%)\end{array}$ & 86.9 & 77.8 & 81.3 & 82.1 & 82.1 & 83.9 & 79.4 & 73.1 & 77.2 & 69.6 & 76.5 & 24.5 & 70.9 \\
\hline $\begin{array}{c}\text { T. bil } \\
(\mathrm{mg} / \mathrm{dL})\end{array}$ & 0.52 & 4.32 & 13.35 & 21.36 & 37.55 & 33.4 & 29.98 & 12.9 & 10.19 & 8.38 & 8.51 & 3.86 & 2.49 \\
\hline $\begin{array}{c}\text { D. bil } \\
(\mathrm{mg} / \mathrm{dL})\end{array}$ & & & & 14.09 & $>22.5$ & $>22.5$ & 20.89 & 9.12 & 7.3 & 6.32 & 6.2 & 2.93 & 1.82 \\
\hline$\underset{(\mathrm{g} / \mathrm{dL})}{\mathrm{Hb}}$ & 9.5 & 11 & 9.4 & 8.8 & 6.7 & 9.1 & 8.4 & 10.1 & 9.8 & 11.4 & 12.6 & 12.2 & 15.4 \\
\hline $\begin{array}{c}\text { Reticulocyte } \\
(\%)\end{array}$ & & & & & $\begin{array}{c}448.3 \\
(21.08)\end{array}$ & $\begin{array}{c}442.8 \\
(16.31)\end{array}$ & $\begin{array}{c}430.6 \\
(16.65)\end{array}$ & $\begin{array}{c}460.6 \\
(14.43)\end{array}$ & $\begin{array}{c}429.7 \\
(13.82)\end{array}$ & $\begin{array}{c}361 \\
(9.95)\end{array}$ & $\begin{array}{c}234.5 \\
(10.02)\end{array}$ & $\begin{array}{l}149.6 \\
(3.75)\end{array}$ & $\begin{array}{c}171.6 \\
(3.55)\end{array}$ \\
\hline \multirow[t]{2}{*}{ Steroid } & & & & & & \multicolumn{6}{|c|}{ (IV methylprednisolone) } & \multicolumn{2}{|c|}{ (PO prednisolone) } \\
\hline & & & & & & $60 \mathrm{mg}$ & $60 \mathrm{mg}$ & $60 \mathrm{mg}$ & $30 \mathrm{mg}$ & $15 \mathrm{mg}$ & $15 \mathrm{mg}$ & $15 \mathrm{mg}$ & $15 \mathrm{mg}$ \\
\hline $\mathrm{OP}$ & & & & & $\begin{array}{l}\text { I \& D } \\
\left(2^{\text {nd }}\right)\end{array}$ & NPWT & NPWT & NPWT & NWPT & $\begin{array}{c}\text { Wound } \\
\text { repair } \\
\left(3^{\text {rd }}\right)\end{array}$ & & $\begin{array}{l}\text { Drain } \\
\text { removal }\end{array}$ & \\
\hline
\end{tabular}

$\mathrm{WBC}=$ white blood cell; $\mathrm{Hb}=$ hemoglobin; $\mathrm{T}$. bil = total bilirubin; $\mathrm{D}$. bil = direct bilirubin; $\mathrm{IV}=$ intravenous; $\mathrm{PO}=$ per oral; OP = operation; $\mathrm{I} \& \mathrm{D}=$ incision and drainage; NPWT = negative pressure wound therapy. 

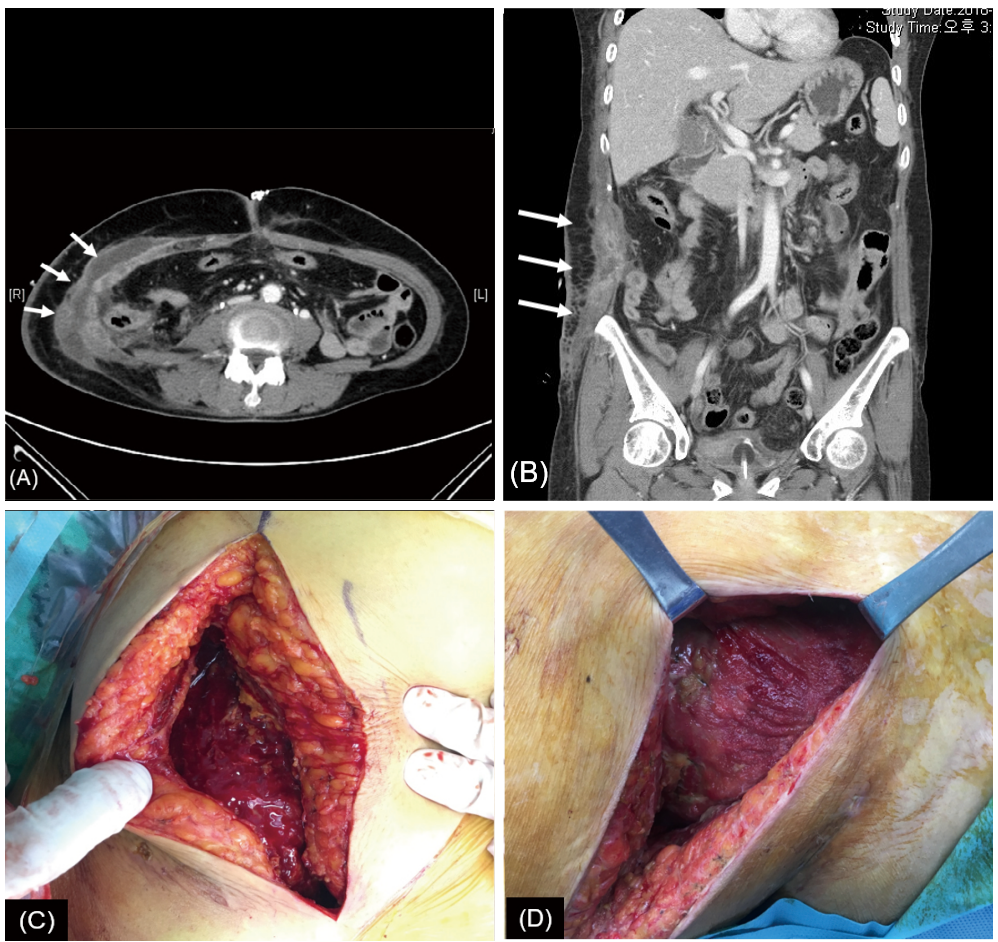

Figure 2. Computed tomography images and surgical findings. Abdomen-pelvis computed tomography confirmed fluid collection and gas formation at the site of the previous right abdominal wall defect (white arrows). (A) Coronal view, (B) axial view, (C) fasciitis of abdominal wall was identified in the operational field of the $2^{\text {nd }}$ surgery, (D) elimination of fasciitis was confirmed in the $3^{\text {rd }}$ surgery.

An abdomen-pelvis CT confirmed fluid collection and gas formation at the site of the previous right abdominal wall defect on the $10^{\text {th }}$ day of hospitalization (Figures $2 \mathrm{~A}$ and $\mathrm{B}$ ). As a result, fasciitis of the site was suspected. Sepsis caused by fasciitis was thought to induce hyperbilirubinemia (total bilirubin: $21.36 \mathrm{mg} / \mathrm{dL}$, direct bilirubin: $14.09 \mathrm{mg} / \mathrm{dL}$ ). Thus, to identify the cause of hyperbilirubinemia, an endoscopic retrograde cholangio-pancreatography was performed on the $11^{\text {th }}$ day of hospitalization to exclude biliary obstruction. On the $12^{\text {th }}$ day of the hospitalization, fever, leukocytosis, and redness of the right abdominal wall were confirmed, and emergency surgery was performed to remove the septic focus. The right hockey stick incision was used to expose the fascia of the affected area, followed by incision and drainage of infectious lesions, and subsequently, the application of negative pressure wound therapy (Figure 2C). Enterobacter cloacae were identified in the bacterial culture from the surgical site and antibiotics (tazobactam/piperacillin) were administered. In addition, when the AIHA evaluation was performed, reticulocyte levels were $21 \%$, lactate dehydrogenase (LDH) levels were $571 \mathrm{U} / \mathrm{L}$, and a direct antiglobulin test (DAT) for anti-IgG2+, and a positive irregular antibody screening confirmed AIHA. The patient was diagnosed with AIHA during the hematology consultation, and was started on methylprednisolone $60 \mathrm{mg}$ intravenously, from the day after the $2^{\text {nd }}$ operation. Subsequently, the levels of her white blood cells and bilirubin decreased, and the patient's condition improved. Wound repair and sump drain insertion were performed on the $19^{\text {th }}$ day of hospitalization (Figure 2D). The drain was removed on the $25^{\text {th }}$ day of hospitalization. On the $37^{\text {th }}$ day of hospitalization the white blood cell count, levels of hemoglobin, and total bilirubin were $6,720 / \mathrm{mL}, 12.5 \mathrm{~g} / \mathrm{dL}$, and $2.49 \mathrm{mg} / \mathrm{dL}$, respectively. The patient was discharged on the $38^{\text {th }}$ day of hospitalization and was prescribed prednisolone (15 $\mathrm{mg}$ ).

\section{Discussion}

A laboratory diagnosis of AIHA depends on the results of a DAT which may be positive for anti-IgG (warm AIHA) and anti-C3d (cold AIHA) antisera, and the presence of laboratory findings supporting hemolysis such as an increased level of serum $\mathrm{LDH}$, reticulocytosis and spherocytosis in peripheral blood smears. In the present case, abdominal wall fasciitis occurred following open surgery for trauma-induced secondary peritonitis with abdominal wall injury, and the patient's condition progressed to sepsis. AIHA was diagnosed based 
on the results of tests performed to determine the cause of hyperbilirubinemia and anemia. Hyperbilirubinemia was noted as a clinical symptom after fasciitis of the abdominal wall. Several previous cases have reported that jaundice was caused by extrahepatic infection [4]. The systematic inflammatory response syndrome caused by sepsis led to hyperbilirubinemia as a consequence of organ dysfunction. Systemic infection causes hepatic dysfunction by increasing hemolysis and inhibiting bilirubin metabolism. Sepsis affects the bile flow which leads to sepsis-associated cholestasis [5]. In this case, it is likely that a combination of these mechanisms caused sepsis-induced hyperbilirubinemia. The infection source responsible for the sepsis was identified on a CT scan, and the patient's condition improved following active source control and use of antibiotics. Incision and drainage eliminated the infected tissues identified as fasciitis for source control, and the risk of reinfection was minimized by performing negative pressure wound therapy. In addition, empirical antibiotics were administered appropriately (before the results of the wound culture from the first surgery were available) as determined by the final culture report.

In addition, reticulocytosis, serum LDH elevation, and a DAT anti-IgG positive (warm AIHA) findings in this case suggested AIHA [6]. In the case of idiopathic AIHA, anemia is mild and a physical examination is usually nonspecific. Compared with idiopathic AIHA which usually presents as mild anemia and a nonspecific physical examination, severe cases with acute onset may exhibit symptoms such as fever, pallor, and jaundice [7]. Massive transfusion is common in patients with abdominal trauma with massive bleeding, therefore AIHA evaluation including autoantibody testing is required when hemoglobin deterioration and clinical symptoms such as fever and jaundice persist after successful bleeding control.

Corticosteroids are the $1^{\text {st }}$ line therapy for AIHA and 1.0-1.5 $\mathrm{mg} / \mathrm{kg} /$ day of prednisone should be maintained for 1-3 weeks until hemoglobin levels reach $10 \mathrm{~g} / \mathrm{dL}$ or more [8]. Previous studies have reported that early use of steroids reduced the likelihood of recurrence of AIHA [9]. In the present case, autoantibody was confirmed by the transfusion test and steroid therapy was started as soon as AIHA was confirmed. If 1 st line therapy was not effective, a splenectomy and rituximab remain the $2^{\text {nd }}$ line therapies, although they may have short term efficacy [10].

This was a case report of the successful treatment of a patient with sepsis and severe hyperbilirubinemia caused by AIHA after abdominal trauma surgery through immediate and multifaceted identification and resolution of causes. This clinical condition should be considered a complication that can occur after open abdominal surgery due to trauma.

\section{Conflicts of Interest}

Ji Young Jang has been the associate editor of Journal of Acute Care Surgery since March 2017, but had no role in the decision to publish this case report. No other potential conflict of interest relevant to this article was reported.

\section{References}

[1] Yoshida M, Marumo Y, Naitoh I, Hayashi K, Miyabe K, Nishi Y, et al. Autoimmune Hemolytic Anemia Obscured by the Obstructive Jaundice Associated with IgG4-related Sclerosing Cholangitis in a Patient with Type 1 Autoimmune Pancreatitis: A Case Report and Review of the Literature. Intern Med 2018;57(12):1725-32.

[2] Go RS, Winters JL, Kay NE. How I treat autoimmune hemolytic anemia. Blood 2017;129(22):2971-9.

[3] Singla B, Singh K, Chawla I. Factors predicting the risk of intra-abdominal sepsis and burst abdomen in patients with abdominal trauma undergoing laparotomy. Int J Health Allied Sci 2017;6(1):5-10.

[4] Pirovino M, Meister F, Rubli E, Karlaganis G. Preserved cytosolic and synthetic liver function in jaundice of severe extrahepatic infection. Gastroenterology 1989;96(6):1589-95.

[5] Chand N, Sanyal AJ. Sepsis-induced cholestasis. Hepatology 2007;45(1):230-41.

[6] Zeerleder S. Autoimmune haemolytic anaemia - A practical guide to cope with a diagnostic and therapeutic challenge. Neth J Med 2011;69(4):17784.

[7] Packman CH. The Clinical Pictures of Autoimmune Hemolytic Anemia. Transfus Med Hemother 2015;42(5):317-24.

[8] Zanella A, Barcellini W. Treatment of autoimmune hemolytic anemias. Haematologica 2014;99(10):1547-54.

[9] Naithani R, Agrawal N, Mahapatra M, Kumar R, Pati HP, Choudhry VP. Autoimmune hemolytic anemia in children. Pediatr Hematol Oncol 2007;24(4):309-15.

[10] Lechner K, Jager U. How I treat autoimmune hemolytic anemias in adults. Blood 2010;116(11):1831-8. 